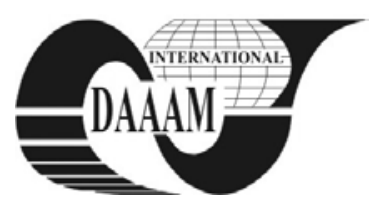

Annals of DAAAM for 2011 \& Proceedings of the 22nd International DAAAM Symposium, Volume 22, No. 1, ISSN 1726-9679 ISBN 978-3-901509-83-4, Editor B. Katalinic, Published by DAAAM International, Vienna, Austria, EU, 2011 Make Harmony between Technology and Nature, and Your Mind will Fly Free as a Bird

\title{
SELECTION OF AS/RSS BY USING FUZZY TOPSIS METHOD
}

\author{
GUELSUEN, B[ahadir]
}

\begin{abstract}
Selecting automated storage and retrieval systems (AS/RS) is a big investment that needs to be handled carefully. Companies that install these systems offer solution with taking their customers' needs and many other factors into consideration. In this study, multi criteria decision making methods are used for selection of automated storage and retrieval systems. Via conversations with experts of a company that installs these systems, factors that customers take into consideration when selecting automated storage and retrieval systems are determined and the selection is done with fuzzy TOPSIS method and four alternatives.
\end{abstract}

Key words: multi-criteria decision making, AS, RS selection, fuzzy TOPSIS

\section{INTRODUCTION}

Decisions about investment are expected to be long-termed and given after long evaluation processes. When making such decisions, one needs to consider not only one criterion, but all criteria that take place in the decision process.

Yet, literature on AS/RS lacks considering various criteria while focusing on optimization issues. A broad survey of literature on AS/RS is given by Roodbergen and Vis (Roodbergen \& Vis, 2009).

Multi-criteria decision making methods are useful when there needs to be a selection among multiple alternatives and more than one factors affect the decision. This study handles the decision process by using fuzzy TOPSIS method. TOPSIS (Technique for Order Preference by Similarity to Ideal Solution) is a MCDM method that was introduced in 1980 by Yoon and Hwang as an alternative method to ELECTRE (Triantaphyllou, 2000). This way, one can consider cost, area, maintainability and other related criteria that affect the decision process. Recent studies that use this method include evaluating sustainable transportation systems (Awasthi et. al., 2011), selecting a scholarship (Uyun \& Riadi, 2011), evaluating the ratings of response alternatives to a simulated oil spill (Krohling \& Campanharo, 2011), logistics center location selection (Erkayman et. al., 2011) and ranking of major air carriers (Torlak et. al., 2011).

\section{FUZZY TOPSIS METHOD}

Fuzzy TOPSIS handles decision processes that don't have crisp data and therefore can't be handled with TOPSIS. Steps of fuzzy TOPSIS can be presented as follows (Erkayman et. al., 2011):

- Step 1: Choose the appropriate linguistic variables for the alternatives with respect to criteria. The linguistic variables are described by triangular fuzzy numbers, such as $\tilde{x}_{i j}=\left(a_{i j}, b_{i j}, c_{i j}\right)$

- Step 2: Construct the fuzzy decision matrix and the normalized fuzzy decision matrix.

$$
\tilde{R}=\left[\tilde{r}_{i j}\right]_{m \times n}
$$

- Step 3: Calculated the weighted normalized fuzzy decision matrix. The weighted normalized value $\tilde{v}_{i j}$ is calculated

$$
\tilde{V}=\left[\tilde{v}_{i j}\right]_{n x J}, i=1,2, \ldots, n, j=1,2, \ldots, J
$$

- Step 4: Define the fuzzy positive-ideal solution (FPIS, $A^{*}$ ) and the fuzzy negative-ideal solution (FNIS, $A^{*}$ ) as

$A^{*}=\left\{\tilde{v}_{1}^{*}, \tilde{v}_{2}^{*}, \ldots, \tilde{v}_{n}^{*}\right\}$

$A^{-}=\left\{\tilde{v}_{1}^{-}, \tilde{v}_{2}^{-}, \ldots, \tilde{v}_{n}^{-}\right\}$where $\tilde{v}_{j}^{*}=(1,1,1)$ and

$\tilde{v}_{j}^{-}=(0,0,0), j=1,2, \ldots . n$.

- Step 5: Calculate the distance of each alternative from $A^{*}$ and $\mathrm{A}^{-}$using following equations:

$$
\begin{aligned}
& D_{j}^{*}=\sum_{j=1}^{n} d\left(\tilde{v}_{i j}, \tilde{v}_{i}^{*}\right) \quad j=1,2, \ldots, J \\
& D_{j}^{-}=\sum_{j=1}^{n} d\left(\tilde{v}_{i j}, \tilde{v}_{i}^{-}\right) \quad j=1,2, \ldots, J
\end{aligned}
$$

- Step 6: Determine the similarities to ideal solution

$$
C C_{j}=\frac{D_{j}^{-}}{D_{j}^{*}+D_{j}^{-}} \quad j=1,2, \ldots, J
$$

- $\quad$ Step 7: Rank the preference order

\section{NUMERICAL EXAMPLE}

In our case, a firm employs fuzzy TOPSIS method to select the most suitable AS/RS for its warehouse. We have four alternatives and six criteria which are given below.

\subsection{Criteria}

- (C1) Cost

- (C2) Technical specification

- (C3) Software.

- (C4) Required area

- (C5) Reliability

- (C6) Maintainability

Please note that C1 and C4 are cost criteria, while others are benefit criteria.

\subsection{Alternatives}

All alternatives have the same number of racks in length.

- (A1): It has a twelve level double-deep rack system located on both sides of the aisle which has one stacker crane.

- (A2): It has a twenty four level single-deep rack system located on both sides of the aisle which has one stacker crane.

- (A3): It has a twelve level back-to-back rack system located on both sides of two aisles, each having one stacker crane.

- (A4): It has a sixteen level rack system located on both sides of an aisle which has one stacker crane. The rack 
frame on one side of the aisle is double-deep, while the rack frame on the other side is single-deep.

\begin{tabular}{|c|c|}
\hline Very low (VL) & $(0,0,1)$ \\
\hline Low (L) & $(0,1,3)$ \\
\hline Medium low (ML) & $(1,3,5)$ \\
\hline Medium (M) & $(3,5,7)$ \\
\hline Medium high (MH) & $(5,7,9)$ \\
\hline High (H) & $(7,9,10)$ \\
\hline Very high (VH) & $(9,10,10)$ \\
\hline
\end{tabular}

Tab. 1. Linguistic variables (Chen, 2000)

\subsection{Application}

Following the steps given in Section 2, firstly, we get the opinions of a group of decision makers in accordance to the linguistic variables (Table 1). The average of the decision makers' ratings for alternatives with respect to the criteria are taken into consideration (Table 2).

\begin{tabular}{|c|c|c|c|c|}
\hline & A1 & A2 & A3 & A4 \\
\hline C1 & F & P & VG & F \\
\hline C2 & P & G & VG & F \\
\hline C3 & VG & F & G & G \\
\hline C4 & G & VP & VG & F \\
\hline C5 & G & F & P & VG \\
\hline C6 & G & VG & G & F \\
\hline
\end{tabular}

Tab. 2. Opinions of decision makers

Then we replace the linguistic variables in Table 2 with relevant fuzzy numbers and obtain the fuzzy decision matrix (Table 3).

\begin{tabular}{|c|c|c|c|c|}
\hline & A1 & A2 & A3 & A4 \\
\hline C1 & $(3,5,7)$ & $(1,3,5)$ & $(9,10,10)$ & $(3,5,7)$ \\
\hline C2 & $(0,0,1)$ & $(5,7,9)$ & $(9,10,10)$ & $(3,5,7)$ \\
\hline C3 & $(9,10,10)$ & $(3,5,7)$ & $(5,7,9)$ & $(7,9,10)$ \\
\hline C4 & $(5,7,9)$ & $(1,3,5)$ & $(9,10,10)$ & $(3,5,7)$ \\
\hline C5 & $(7,9,10)$ & $(3,5,7)$ & $(1,3,5)$ & $(9,10,10)$ \\
\hline C6 & $(5,7,9)$ & $(9,10,10)$ & $(7,9,10)$ & $(3,5,7)$ \\
\hline
\end{tabular}

Tab. 3. The fuzzy decision matrix

Later, we construct the normalized fuzzy decision matrix (Table 4).

\begin{tabular}{|c|c|c|c|c|}
\hline & A1 & A2 & A3 & A4 \\
\hline C1 & $(0.14,0.20,0.33)$ & $(0.20,0.33,1.00)$ & $(0.10,0.10,0.11)$ & $(0.14,0.20,0.33)$ \\
\hline C2 & $(0.00,0.00,0.10)$ & $(0.50,0.70,0.90)$ & $(0.90,1.00,1.00)$ & $(0.30,0.50,0.70)$ \\
\hline C3 & $(0.90,1.00,1.00)$ & $(0.30,0.50,0.70)$ & $(0.50,0.70,0.90)$ & $(0.70,0.90,1.00)$ \\
\hline C4 & $(0.11,0.14,0.20)$ & $(0.20,0.33,1.00)$ & $(0.10,0.10,0.11)$ & $(0.14,0.20,0.33)$ \\
\hline C5 & $(0.70,0.90,1.00)$ & $(0.30,0.50,0.70)$ & $(0.10,0.30,0.50)$ & $(0.90,1.00,1.00)$ \\
\hline C6 & $(0.50,0.70,0.90)$ & $(0.90,1.00,1.00)$ & $(0.70,0.90,1.00)$ & $(0.30,0.50,0.70)$ \\
\hline
\end{tabular}

Tab. 4. Normalized fuzzy decision matrix

The averages of the weights for each criterion are also calculated, which are $0.15,0.21,0.13,0.18,0.18$ and 0.15 , respectively. Then, the weighted normalized values are calculated and they form the matrix given in Table 5.

\begin{tabular}{|c|c|c|c|c|}
\hline & A1 & A2 & A3 & A4 \\
\hline C1 & $(0.02,0.03,0.05)$ & $(0.03,0.05,0.15)$ & $(0.02,0.02,0.02)$ & $(0.02,0.03,0.05)$ \\
\hline C2 & $(0.00,0.00,0.02)$ & $(0.11,0.15,0.19)$ & $(0.19,0.21,0.21)$ & $(0.06,0.11,0.15)$ \\
\hline C3 & $(0.12,0.13,0.13)$ & $(0.04,0.07,0.09)$ & $(0.07,0.09,0.12)$ & $(0.09,0.12,0.13)$ \\
\hline C4 & $(0.02,0.03,0.04)$ & $(0.04,0.06,0.18)$ & $(0.02,0.02,0.02)$ & $(0.03,0.04,0.06)$ \\
\hline C5 & $(0.13,0.16,0.18)$ & $(0.05,0.09,0.13)$ & $(0.02,0.05,0.09)$ & $(0.16,0.18,0.18)$ \\
\hline C6 & $(0.08,0.11,0.14)$ & $(0.14,0.15,0.15)$ & $(0.11,0.14,0.15)$ & $(0.05,0.08,0.11)$ \\
\hline
\end{tabular}

Tab. 5. Weighted normalized fuzzy decision matrix
Later, we calculate the distance of each alternative from $\mathrm{A}^{*}$ and $\mathrm{A}^{-}$(Table 6).

\begin{tabular}{|c|c|c|}
\hline & $D_{j}^{*}$ & $D_{j}^{-}$ \\
\hline A1 & 5,55 & 0,47 \\
\hline A2 & 5,39 & 0,66 \\
\hline A3 & 5,49 & 0,52 \\
\hline A4 & 5,46 & 0,56 \\
\hline
\end{tabular}

Tab. 6. Distances from positive-ideal and negative ideal solutions

Finally, we determine the similarity of each alternative to the ideal solution (Table 7) and rank the preference order.

\begin{tabular}{|c|c|c|}
\hline & $C C_{j}^{*}$ & Rank \\
\hline A1 & 0,0777 & 4 \\
\hline A2 & 0,1096 & 1 \\
\hline A3 & 0,0871 & 3 \\
\hline A4 & 0,0925 & 2 \\
\hline
\end{tabular}

Tab. 7. Similarity of each alternative to the ideal solution

\section{RESULTS AND CONCLUSION}

This study aimed to present an alternative way to professionals and researchers in deciding on the design of an AS/RS. The fuzzy TOPSIS method was employed to handle the decision process. As a result, the preference order is A2, A4, A3 and A1. One should keep in mind that replacing one of the alternatives with a new one might change the result and it's essential to define the criteria and make the ratings properly for each application of this method.

For further research, criteria and the alternatives can be altered. Also, other fuzzy decision making methods can be employed. We intend to use other fuzzy MCDMs for this problem and see how these methods will result.

\section{REFERENCES}

Awasthi, A.; Chauhan, S. A. \& Omrani, H. (2011). Application of Fuzzy TOPSIS in Evaluating Sustainable Transportation Systems. Expert Systems with Applications, 38, 1227012280.

Chen, C. (2000). Extensions of the TOPSIS for group decisionmaking under fuzzy environment. Fuzzy Sets and Systems, $114,1-9$

Erkayman, B.; Gundogar, E.; Akkaya, G. \& Ipek, M. (2011). A Fuzzy TOPSIS Approach for Logistics Center Location Selection. Journal of Business Case Studies, 7, 3, 49-54

Krohling, R. A. \& Campanharo, V. C. (2011). Fuzzy TOPSIS for Group Decision Making: A Case Study for Accidents with Oil Spill in the Sea. Expert Systems with Applications, 38, 4190-4197

Roodbergen, K. J. \& Vis, I. F. A. (2009). A Survey of Literature on Automated Storage and Retrieval Systems. European Journal of Operational Research, 194, 343-362

Torlak, G.; Sevkli, M.; Sanal, M. \& Zaim, S. (2011). Analyzing Business Competition by Using Fuzzy TOPSIS Method: An Example of Turkish Domestic Airline Industry. Expert Systems with Applications, 38, 3396-3406

Triantaphyllou, E. (2000). Multi-Criteria Decision Making Methods: A Comparative Study, Kluwer Academic Publishers, Boston

Uyun, S. \& Riadi, I. (2011). A Fuzzy Topsis Multiple-Attribute Decision Making for Scholarship Selection. Telkomnika, 9, $1,37-46$ 